\title{
Research on the continuation of mining works in the license perimeter of the Peşteana Nord quarry
}

\author{
Daniela Ionela Ciolea $^{1 *}$, Vasile Bobei ${ }^{2}$, Tiberiu $\mathrm{Rusu}^{2}$, Ioana Ionel$^{3}$, and Tudor Andrei \\ Rusu $^{2}$ \\ ${ }^{1}$ University of Petroșani, Department of Environmental Engineering and Geology, Universitatii \\ Street, no. 20, Petrosani, Romania \\ ${ }^{2}$ Technical University of Cluj Napoca, Department of Environmental Engineering and Sustainable \\ Development Entrepreneurship, Bulevardul Muncii, 103-105, Cluj Napoca, Romania \\ ${ }^{3}$ Polytechnic University of Timisoara, Department of Thermal Machines and Transport, Bv. M. \\ Viteazu, no. 1, Timisoara, Romania
}

\begin{abstract}
Exploitation works at the North Pesteana Quarry is located in areas with mineral energy resources, and contributes to ensuring the country's energy security, based on an efficient system of supply of primary resources, production, transport, distribution and supply, to ensure food of all consumers in terms of accessibility, availability and affordability of prices, taking into account the evolution of the quality of the environment. The exploitation surface is isolated from the protected area Jiu Corridor ROSCI0045 through the neighborhoods from the eastern limit-the regularization channel of the river Jiu and the villages Balteni, Peșteana Jiu, Cocoreni, Olari and the neighborhoods from the western limit - the villages Valea cu Apa, Pesteana de Jos, Hotaroasa, Urdari. Lignite mining works do not affect the integrity of the protected natural area; by carrying out the works, the artificial barriers between the natural and the anthropic terrain are not created. The paper presents the results of the research undertaken in 2019 through the technical expertise in File no. 14666/3/2017*, Archive of the Bucharest Tribunal [1]. Measures are proposed to prevent, reduce and, where possible, offset significant adverse effects on the environment, including: measures for the protection of water quality, air quality, protection against noise and vibration, in the field of soil and subsoil quality, biodiversity and measures for the rehabilitation of the land for its subsequent use, etc.
\end{abstract}

\section{Introduction}

Oltenia Energy Complex, has hydrogeological studies in order to avoid generating a negative impact on groundwater layers, respectively on the environment $[1,7]$.

\footnotetext{
* Corresponding author: danielaciolea@upet.ro
} 
The hydrogeological study aims to identify potential water sources - surface or deep and establish catchment conditions both to ensure the necessary flow and to avoid generating a negative impact on groundwater layers, respectively on the environment.

The water management permit is the act that conditions from a technical and legal point of view the operation or operation of new objectives, built on water or related to surface, groundwater.

The opening of the Peşteana Nord Quarry began in 1980, through a trench located at the northern limit of the exploitation perimeter, where the deposit conditions were the most favorable for the short-term realization of a coal production. [2].The opening works took place until 1985, when a quantity of 1039 thousand tons of coal was extracted [3].

The advance of the quarry continued from north to south, the tailings resulting from the discovery being deposited in the outer dump located in the northern part of the exploitation perimeter.

The mining objective was approved at site level and technical and economic indicators through the projects:

- "Opening and exploitation of lignite reserves in the Peșteana-Gorj mining field, at a capacity of 4,500,000 tons / year of lignite, during 1974-1985", symbol 810-05C / 1974. The indicators were approved by H.C.M. no. 1693/1974.

- "Works for maintaining and developing the capacity at the Pesteana quarry, Gorj county, from 4,500 thousand tons / year to 5,500 thousand t / year during 1983-1988", symbol 810234 / A. The indicators were approved by H.C.M. no. 20/1985 [1].

The exploitation activity, starting with the year 2000, is carried out based on the exploitation license, issued by ANRM Bucharest with no. 1457/2000, for a period of activity of 20 years (starting with 2004), approved by GD 319/2004.

\section{Methodology}

In impact assessments, the environment must be considered as a complex system governed by multiple laws, in which any intervention or anthropogenic activity, which changes the balance of resource use, generates a chain of reactions that can cause one or more impacts on the environment.

The location of the project has been identified, it is located in areas with mineral energy resources, and contributes to ensuring the country's energy security, based on an efficient system of supply of primary resources, production, transport, distribution and supply, ensuring continuous supply of all consumers in terms of accessibility, availability and affordability of prices, taking into account the evolution of the quality of the environment.

The exploitation surface is isolated from the protected area Jiu Corridor ROSCI0045 through the neighborhoods from the eastern limit - the regularization channel of the river Jiu and the villages Bâlteni, Peșteana Jiu, Cocoreni, Olari and the neighborhoods from the western limit - the villages Valea cu Apa, Peșteana de Jos, Hotăroasa, Urdari. Lignite mining works do not affect the integrity of the protected natural area; by carrying out the works, the artificial barriers between the natural and the anthropic terrain are not created [1].

The organization of the coal mining activity in the Pesteana Nord quarry, besides the actual excavation, transport and dump works, requires the execution of specific works arrangement of access and transport roads, hydrotechnical arrangements, drying works, each of them constituting elements disturbance, modification and interruption of the continuity of the environment.

In the specific conditions of our country, the environmental strategy has as first objective the renaturalization of the lands used for other activities, without technological tasks. The cultivation of land used for exploitation activities is an objective requirement as 
they have been removed from the productive circuit, affecting the landscape and environmental factors over more or less extensive areas [6].

By carrying out the project, there is no extension of the North Peșteana Quarry outside the license perimeter, but a production capacity is maintained within the same mining perimeter, cf. GD 319/2004.

Dolj County Council as Administrator of the protected area Jiu Corridor ROSCI0045 issues in April 2016, Favorable Opinion no. 7719 / 18.04.2016 for the continuation of the exploitation works at the North Peşteana Quarry.

\section{Results and discussions}

The report on the environmental impact study for the project "continuation of mining works in the license perimeter of the North Peșteana Quarry" scientifically deals with all aspects provided by the legislation in force.

The Environmental Agreement sets out measures to prevent, reduce and, where possible, offset significant adverse effects on the environment. Thus are provided [1]:

- measures and conditions that must be observed during the project;

- measures during operation and the effect of their implementation;

- measures for closure / demolition / decommissioning and rehabilitation of the land for later use, as well as the effect of their implementation;

- measures for the protection of water quality, air quality, protection against noise and vibration, in the field of soil and subsoil, in the field of biodiversity;

- the environmental monitoring plan, indicating the environmental components to be monitored.

The activity of mining resources is regulated by the Mining Law no. 85/2003, in this case the investment being started for the Peșteana Quarry before 1990, 1975 - and in accordance with the legislation in force at that date, the necessary authorizations were obtained, according to Decree no. 144/29 March 1958, being issued: The authorization for the execution of works no. 189 / 10.02.1975, [4]. For the continuation of the exploitation works at the Peşteana Nord Quarry, no construction works are considered, which require an urbanism certificate. Regarding the start of the environmental impact assessment procedure, there is Notification no. 1358 / 28.01.2015 / CEO; 909 / 28.01.2015 / APM Gorj, and the attached plans. Through the Report on the environmental impact study "Continuation of mining works in the license perimeter for Peşteana Nord Quarry proposed to be located in the suburbs / urban areas of Urdari, Bâlteni and Popșloru communes, Gorj county" was scientifically demonstrated by SC Research Institute Scientific, Technological Engineering and Mining Design on Lignit-SA Craiova, the fact that the project does not have a negative impact on environmental factors and on protected areas in the neighborhood.

The paper highlights the measures needed to prevent and reduce the impact of water, air, soil, noise, waste, biodiversity, protected areas, human settlements.

\subsection{Measures during the realization of the project [1]}

A project that aims to exploit energy resources in the quarry, such as lignite at Peşteana, requires a series of environmental protection measures. Some of these measures will be set out below, for all environmental factors considered.

\subsubsection{Water}

- application, in case of need, of all measures to prevent and combat accidental pollution according to the provisions in force; 
- prohibition of the storage of any type of waste in surface waters;

- the revisions and repairs to the equipment will be made periodically according to the graphs and technical specifications, and the fuel supply will be made only in areas specially arranged for this purpose;

- the handling of fuels is done in such a way as to avoid leaks and their scattering on the ground;

- construction and maintenance of guard ditches that collect rainwater, in the pace of progress of opening, preparation and operation.

\subsubsection{Air}

- the maintenance in perfect working order of the equipment and means of transport, the periodic performance of their technical inspection, and in case of defects are found, their remedy as soon as possible;

- imposing speed restrictions on means of transport on the access road;

- use of equipment and means of transport with high-performance engines due to Euro pollutant retention systems.

\subsubsection{Soil}

- storage of fuels, lubricants, waste, residues that would lead to soil pollution, only in areas and perimeters specially designed for this purpose outside the perimeter of operation and in strict compliance with the regulations in force on environmental protection;

- keeping records of unrecovered waste and whose uncontrolled release may endanger the quality of the soil or other components of the environment;

- the fuel supply of the means of transport and of the equipment will be done from the oil products stations, and in case of technical impossibility the supply of the equipment from the quarry will be done with maximum attention;

- checking the integrity of fuel and lubricant containers and, in the event of a fault, repairing it as soon as possible;

- checking the integrity of the concrete platforms on which petroleum products and / or technological waste (waste oils, etc.) are stored;

- in case of accidental pollution, the volume of soil will be removed, temporarily stored and remedied by specialized and authorized units;

- in order not to lose the quality of fertile soil (structure and soil with humus), the uncovered soil must be used immediately by depositing it as fertilizer material on the surfaces arranged on the dump or other surfaces, even on natural lands, to increase their fertility.

\subsubsection{Noise}

- use of equipment and means of transport with high-performance engines equipped with noise attenuators;

- observance of transport routes and approved transport timetable.

\subsubsection{Waste}

- scrap metal and other reusable waste are disposed of according to special management plans and recovered by specialized companies;

- construction waste (decommissioning of temporary construction, barracks if applicable) is disposed of by transport and stored on an authorized site or used as backfill; 
- no waste will be deposited in the riverbeds or in the immediate vicinity [5].

\subsubsection{Biodiversity / natural areas:}

The stage of preparation of the mining field for exploitation:

In order to reduce the impact due to vegetation removal:

- the use of silent equipment and means of transport to reduce noise;

- maintaining the operation at the optimum designed parameters and the periodic verification of all the technological equipment and specific means of transport and of all the activities carried out during the entire working period;

- spraying the access roads in order to reduce the sedimentable dusts in order to avoid their deposition on the canopy of the trees;

- in case of accidental pollution during the activity, immediate measures will be taken to remove the pollution generating factors and the authorities responsible for environmental protection will be notified. Accidentally contaminated surfaces will be excavated, and the affected volume of soil will be stored in special containers, sealed and subsequently disposed of by specialized and authorized companies;

In order to reduce the impact, it is recommended to carry out work outside the breeding seasons of the species. Large mammals, however rare and without stable populations in the project area will leave this area. Airborne nuisances as well as noise can be stressors for area maifers.

Exploitation stage of the geological extract:

To protect the flora, consider:

- avoidance of non-recoverable and disordered losses of some materials (lubricants, fuels);

- measures to limit dust emissions

- arranging and improving the lands freed from technological burdens so that they can be recultivated;

The problem of local fauna is also related to the reconstruction of the existing biotope before the degradation of the area, which is partly possible by rearranging the mining perimeter but only at the time of closing the quarry.

\subsubsection{Scenery}

After the occupation of the agricultural lands and after reaching the final excavation quotas and the depletion of the deposit, the arrangement and afforestation of the land used for lignite exploitation and the arrangement for rendering in the economic circuit, in order to introduce them in the productive circuit, with the previous use of mining works.

Also, at the final removal from the forest fund, the provisions of Order 924/2011 on the Methodology for establishing the value equivalence of lands and for calculating the monetary obligations for the final removal or temporary occupation of lands from the national forest fund will be observed. The lands returned to the productive and agricultural forestry circuit will be integrated in the predominant landscape in the area.

\subsubsection{Human settlements}

Taking all measures in the agricultural perimeter and in their adjacent area as well as along the access roads, in order to avoid accidents or damages with major impact on the health of the population. 


\subsection{Measures during operation and the effect of their implementation [1]}

\subsubsection{Water}

- construction and maintenance of guard ditches that collect rainwater, in the pace of progress of opening, preparation and operation;

- application, in case of need, of all measures to prevent and combat accidental pollution according to the provisions in force;

- the maintenance of the administrative premises treatment systems in order to classify the discharged waters within the allowed limits and the observance of the technical norms of operation of the installations;

- prohibition of the storage of any type of waste in surface waters;

- the revisions and repairs to the equipment will be made periodically according to the graphs and technical specifications, and the fuel supply will be made only in areas specially arranged for this purpose;

- the handling of fuels is done in such a way as to avoid leaks and their spreading on the ground;

- to ensure throughout the operation measures to verify the discharged water and to identify solutions for the prevention of pollution and remediation in the event of accidental discharges of dangerous substances.

\subsubsection{Air}

- capture the dust at the source by casing the dust generating equipment;

- improving the technical condition of the access road by repairing and permanently maintaining it in good technical condition, along its entire length;

- maintaining equipment and means of transport in good working order, carrying out inspections and maintenance in specialized workshops;

- training of the personnel who will work in the workplace, on fire prevention and extinguishing measures and on environmental protection measures;

- drawing up a working schedule for the means of transport, specifying the route and speed of traffic, the mode of transport of the cargo;

- equipping the working point with a water tank equipped with a spraying device, for interventions in case of fires and for reducing the amount of dust raised in the atmosphere;

- movement of coal stocks to prevent self-ignition of coal in very hot periods;

- coal compaction during stack formation;

- use of production coatings to prevent air access inside the coal stack, cover the surface and slopes with: coal dust, slag dust in a layer of $10-15 \mathrm{~cm}$, compacted, anthracite $(0-3 \mathrm{~mm})$ sprayed with oiled and compacted. You can also use clay bitumen paste ( $45 \%$ bitumen, $25 \%$ water, $30 \%$ clay), which is applied on the surface of the stack in liquid form, in a layer of 2-3 mm. The use of clay bitumen as a protective layer is only possible when the ambient temperature is $0{ }^{\circ} \mathrm{C}$;

- the use of inhibitors in order to reduce the qualitative losses of coal;

- in order to prevent the self-ignition of the coal in the outcropping layers, it is not completely uncovered, leaving a tailings layer of approx. $10-15 \mathrm{~cm}$;

- the abandonment of coal pillars in the exploited space will be avoided as much as possible;

- for the insulation of a fire or an abandoned coal pillar, areas of total backfill or siltation will be created;

- the introduction of foreign materials into coal, especially wood, should be avoided; 
- monitoring the temperature through probes on steel pipes to the bottom of the stack, where thermometers are lowered, measuring the temperature every $2 \mathrm{~m}$ depth; when the temperature exceeds $40{ }^{\circ} \mathrm{C}$, the control is done at the interval of $12 \mathrm{~h}$, and if the temperature exceeds $60{ }^{\circ} \mathrm{C}$, the coal is consumed immediately;

- rendering in the productive circuit the lands left free of technological loads in order to limit the spread of dust in the atmosphere;

- minimizing emissions to air, through the proper design and maintenance of mining facilities, through appropriate operational procedures and specific emission control procedures.

\subsubsection{Soil}

- rendering in the productive circuit the lands left free of technological loads;

- avoiding the advanced discovery in the face of lignite mining works to remove the regressive erosion of the uncovered land and limiting the action of precipitation and winds;

- permanent verification of the condition of the working slopes in the quarry;

- ensuring the necessary conditions for the directed evacuation of surface waters, through gutters executed along the slope; provided that there is no possibility of directing the water that accumulates at the foot of the dump outside the perimeter, their discharge will be made through pumping stations;

- to ensure the observance of the slope angles provided by geotechnical studies elaborated until now;

- to ensure the compaction of the dump, as well as the observance of the slope angles;

- in the scaffolding process, special attention will be paid to the way the hall steps are twinned with the final slopes of the quarry, in order not to create favorable areas for water accumulation in the body of the dump or at its base and to increase the stability of the land around the quarry;

- the vegetal soil will be stored separately and will be used for the renaturation of the land within the environmental restoration works;

- in the exploitation perimeter where the sloping lands have a tendency to slip and this can degrade the deposit, measures will be taken to stabilize them.

\subsubsection{Noise}

- isolating, as far as possible, the installation and choosing the quietest technologies possible;

- encapsulation of conveyor belts in areas where noise is a local problem;

- orientation of sensitive points according to the prevailing winds;

- the size of the distance between the noise sources and the protected buildings;

- sound-absorbing soil (grass and vegetation);

- shielding by descending or making screens between installations and sensitive points; with a more psychological result, vegetation screens (efficiency $1 \ldots 2 \mathrm{~dB}$ for $10 \mathrm{~m}$ dense vegetation with permanent leaves).

\subsubsection{Waste}

- the sterile rocks resulting from the lignite deposit uncovering works are deposited in the inner dump;

- the tailings are deposited under the conditions of the rock mixture resulting directly from the excavations, as unselected material with a pronounced homogeneity of granularity and non-uniformity of geotechnical parameters. 


\subsubsection{Biodiversity}

- avoidance of non-recoverable and disordered losses of materials (lubricants, fuels);

- measures to limit ulcer emissions;

- arranging and improving the fields released by technological loads so that they can be recultivated;

- the problem of local fauna is also related to the reconstruction of the existing biotope before the degradation of the area, which is partly possible by redevelopment of the mining perimeter but only at the time of closure of the quarry;

- once the flora and fauna are reinstated, as well as the execution of the other works of protection and restoration of the environment, the microclimate conditions are restored.

\subsubsection{Cultural heritage}

For a better understanding of the effects of lignite mining on the microclimate, species migration, flora and fauna, it is necessary to carefully monitor these activities and their impact.

In the situation where on the site of the designed works, following the excavations, possible archaeological sites are identified, the works will be stopped and a representative of the competent authorities will be contacted in order to establish the necessary solutions.

Regarding the measures for closure / demolition / decommissioning and rehabilitation of the land for later use, it is mentioned: upon reaching the exploitation quotas approved by ANRM through the closure plan, the lands will be remodeled and arranged accordingly so as to re-enter the productive economic circuit.

The quarry areas that have been exploited will be greened by stabilization and gliding works with species resistant to bioclimatic conditions in the area.

The implementation of the mining project will determine the appearance of some forms of negative impact, on different durations, on the social and economic life in the community [6]:

- diminution of land areas occupied by technological flows and which is a source of income for human settlements in the area;

- affecting the water sources of the localities (groundwater and springs) in general of the individual wells;

- industrial landscapes specific to excavation and dumps for long periods of time, instead of natural ones.

The continuation of the exploitation represents an extension of the life cycle of the exploitation, the period that contributes to the achievement of the desideratum of the sustainable development and that makes the transition slower towards the closure, preparing at the same time the community and the local economy.

This can avoid social and environmental shocks and greatly reduce the risks associated with site closure and remediation.

Following the analysis of the previously mentioned forms of impact and in the conditions of the spatial relationship of the location with the inhabited areas, it can be appreciated that the socio-economic environment in the area will not be significantly affected by lignite deforestation and exploitation activities.

\section{Conclusions}

Measures are proposed to prevent, reduce and, where possible, offset significant adverse effects on the environment, including: measures for the protection of water quality, air 
quality, protection against noise and vibration, in the field of soil and subsoil quality, biodiversity and measures for the rehabilitation of the land for its subsequent use, etc.

The location of the project, the continuation of the mining works at the Peşteana Nord Quarry, is found in areas with energetic mineral resources and is located outside the protected natural areas, at very great distances from them. Thus, there is no impact of the lignite mining works on the ROSCI0045 Jiu Corridor site.

The development and extension of the quarry (within the limits of the approved License) will bring important benefits to the local economy and communities, including:

- continuity of activities, in coal mining, for the local labor force, specialized mainly in coal mining;

- improving the quality of the environment by applying mitigation measures that will solve the negative environmental impact;

- training and improvement in the field of modern mining techniques and related activities (training programs for mining, operation of equipment, operation and maintenance of facilities, information technology, measurement and control systems);

- concluding contracts with local companies for activities such as: building maintenance, supply of fuels and lubricants, supply of spare parts, service for machinery, service for office activities, waste management (recycling and reuse) and other types of services and supplies;

- increasing the local budget by collecting taxes with a potential positive impact on general social conditions; • potential increase in property value;

- infrastructure improvement.

- construction of new homes at current standards for owners affected by coal mining; ensuring the improvement of the quality of life and living conditions;

- conditions for the implementation of economic and social programs to ensure the complex and sustainable development of the area.

The continuation of the exploitation works in the mining perimeter will generate direct and indirect incomes coming from taxes, duties and royalties and will maintain the jobs for the analyzed period in the field of quarry operation, as well as in the field of auxiliary activities.

In order to meet the desideratum regarding the objectives of the new EU energy policy, Romania will consider the achievement of a diversified, balanced energy mix, with the efficient use of all internal primary energy resources, as well as modern technologies that allow the long-term use of fossil fuels with low greenhouse gas emissions, renewable energy sources, and nuclear energy.

\section{References}

1. D. I. Ciolea, Expertise Report, Dossar no. 14666/3/2017*, Archive of the Bucharest Tribunal, (București, 2019)

2. I. Onica, Impactul exploatărilor de substanţe minerale utile asupra mediului, Editura Universitas, (Petroşani, 2001)

3. D. Fodor, G. Baican, Impactul industriei miniere asupra mediului, Editura Infomin, (Deva, 2001)

4. C. Herbst, I. Lețea, Resursele energetice ale României, Editura Științifică, (București, 1974)

5. V. R. Pascu, Managementul deşeurilor, Editura Universităţii „Lucian Blaga” (Sibiu, 2009)

6. ICPML Craiova, Raport la studiu de impact asupra mediului - UMC Peșteana - Nord, (Craiova, 2015)

7. https://www.ceoltenia.ro/en/responsabilitate/mediu/procedura-eim/ 